\title{
Quantum-size effects in semiconductor heterosystems
}

\author{
L.A. Matveeva, E.F. Venger, E.Yu. Kolyadina, P.L. Neluba \\ V.E. Lashkarov Institute of Semiconductor Physics NAS of Ukraine, \\ 45, prospect Nauky, 03028 Kyiv, Ukraine \\ E-mail:matveeva@isp.kiev.ua
}

\begin{abstract}
Created on the basis of $\mathrm{Si}, \mathrm{GaAs}$ and $\mathrm{C}_{60}$ fullerenes were low-dimensional heterostructures with a surface quantum-size effect at the film-substrate interface. There have been defined technological conditions of its appearance. Using modulation electroreflectance spectroscopy, calculated were spectral broadening parameters, the energy relaxation time of excited light charge carriers, the energy of quantized levels and the width of the quantum wells.
\end{abstract}

Keywords: heterostructures, interface, electroreflectance, electronic parameters, quantum-size effect.

Manuscript received 27.01.17; revised version received 11.04.17; accepted for publication 14.06.17; published online 18.07.17.

\section{Introduction}

Physical properties of heterosystems are not a simple sum of the contacting materials. They acquire new electronic and optical properties due to appearance of the surface potential, internal mechanical stresses, built-in electric fields and quantum size effects at the filmsubstrate interface. When the size of the region of free charge carrier localization becomes comparable with the free length, their movement is restricted to one, two or three directions. Low-dimensional heterosystems have a different energy dependence of the electron density of states in the band structure, which depends on their dimensions. Decreasing localization of free charge carriers reduces heterosystem dimensionality. These heterosystems can be two-dimensional with quantum wells, one-dimensional in the case of quantum wires and zero-dimensional when quantum dots are available. The energy dependence of the density of electron states in these low-dimensional structures is different. Monotonous quadratic energy dependence, which is typical for bulk sample, becomes discrete. For twodimensional structures, it is monotonous and changes stepwise with increasing the energy of charge carriers. For one-dimensional structures, it is continuous and sawtooth, and is set of dashed lines for zero-dimensional structures [1]. It is necessary to distinguish between the bulk quantum-size effect in heterosystems with a rectangular quantum well, where quantized are both types of charge carriers, from the surface quantum-size effect, when quantized is only one their type in the triangular quantum well. Transformation of the band structure in the low-dimensional heterosystems leads to changes in their electronic and optical properties [2].

Silicon is still the main material of semiconductor electronics. Gallium arsenide ranks second after the silicon and is also widely used in optoelectronics. On its basis, there are LEDs, lasers, photodetectors and solar cells. Sulfidation of the GaAs surface decreases the density of surface electronic states and increases the intensity of photoluminescence [3]. Development of technology for production of fullerenes in the form of film material on different substrates expands the use of nanostructures with $\mathrm{C}_{60}$ fullerenes [4], including solar cells $[5,6]$ and sensors of physical quantities [7].

Modulation electroreflectance spectroscopy has considerable advantages in comparison with classical reflectance and transmittance spectroscopy. When investigating the band structure of semiconductors, their electronic and optical properties, the sensitivity of this method is several orders of magnitude more sensitive than the classical optical methods. The advantage of the modulation spectra is that they reveal the thin structure usually hidden unstructured background. The electroreflectance method is more sensitive to the band structure of the semiconductors, because its signal is the 
third derivative of the optical constants. The signal exists at the critical points of the Brillouin zone only in the region of direct transitions, and it disappears at some distance from the critical point. The electroreflectance signal is determined by the optical and electronic properties of the surface under study [8-10].

The purpose of this study was to find and study the surface quantum-size effect in semiconductor heterosystems based on silicon, gallium arsenide, and $\mathrm{C}_{60}$ fullerene by using modulation electroreflectance spectroscopy.

\section{Experiment}

Measurements of electroreflectance spectra in the heterosystems were carried out with the electrolytic method. Essence of the method is to register changes in the reflectivity of the semiconductor surface $\Delta R / R$ upon application of a weak modulating electric field. Measurements were made using the setup based on the DMR-4 monochromator with automatic registration of spectra on the screen in a linear energy scale. The spectral resolution was $3 \mathrm{meV}$. The sensitivity of this apparatus for $\Delta R / R$ signal measurement reached $10^{-6}$, and the accuracy of measuring intensity was $2 \%$. The signal was recorded within the spectral range 1.5 to $3.5 \mathrm{eV}$ at room temperature in a weak-field measuring regime. The modulating voltage did not exceed $0.7 \mathrm{~V}$.

The samples were placed into a silica electrolytic cell with $0.1 \mathrm{~N}$ water $\mathrm{KCl}$ solution. From the photomultiplier, the signal was fed to the selective amplifier U2-6 and registered using a synchronous detector. This method allowed us to obtain information about the band structure of heterosystem on its surface and in the region of the film-substrate interface, as well as to detect its change depending on the technological conditions of heterosystems manufacturing and influence on them caused by external actions.

In order to obtain heterosystems with the quantum size effect, we used anisotropic chemical etching of $\mathrm{Si}$ [11] and GaAs [12] surfaces, sulfide passivation of GaAs surface by chemical etching [13], neutron irradiation and annealing of Si wafers [14], as well as thermal vacuum deposition of $\mathrm{C}_{60}$ fullerenes on $\mathrm{Si}$ and the cover glass substrate [15]. An analysis of the electroreflectance spectra in a specific region of the $k$ space in the Brillouin zone for a direct transition makes it possible to determine the transition energy $E_{g}$, the phenomenological Lorentz broadening parameter $\Gamma$, which allows for dissipation processes in the electron transition, and the energy relaxation time $\tau$ of the light excited charge carriers. These parameters were determined using the three-point method by Aspnes [16].

\section{Results and discussion}

The results of measurement of the electroreflectance spectra of the initial $n$-Si (100) surface and anisotropically etched in $\mathrm{HF}: \mathrm{HNO}_{3}=20: 1$ mixture in the course of $20 \ldots 30 \mathrm{~min}$ depicted in Fig. 1. The electroreflectance signal of the initial surface $\mathrm{Si}$ was recorded in the region of 3.2 to $3.55 \mathrm{eV}$ (curve 1, Fig. 1). According to the electron band structure of silicon, this electroreflectance signal corresponds to direct transitions that occur between the valence and conduction bands at the center of the Brillouin zone. In the process of anisotropic chemical etching, the surface of the $\mathrm{Si}(100)$ plate dimmer, and microrelief appears on the surface. The $\mathrm{SiO}_{2}$ layer of crystal modification of $\beta$-crystoballite forms at the plate surface [11]. The electroreflectance spectrum of anisotropically etched silicon surface is shown in Fig. 1, curve 2. There are inversion of the polarity signal, the value of the phenomenological parameter $\Gamma$ decreases, and peaks are separated by $40 \mathrm{meV}$.

At the initial surface of the silicon substrate, and also after the oxide layer is removed from the microrelief surface, the bands undergo depletion bending. The surface is depleted of electrons, and the band are bent upward (Fig. 1, spectrum 1). On the $\mathrm{Si}$ surface under a layer of $\mathrm{SiO}_{2}$, the potential is of enrichment type, and the bands are bent downward (Fig. 1, spectrum 2). The substrate surface is enriched with electrons, and this leads to the change in the electroreflectance signal phase at the interface $\mathrm{SiO}_{2}-\mathrm{Si}$.

The doublet nature of the peaks of electroreflectance in anisotropically etched silicon can be explained by the effect of surface quantization of the electron energy in the enriched surface layer of silicon at the boundary. Between the $\mathrm{SiO}_{\mathrm{x}}$ layer and silicon, there is a quantum well. Availability of $2 \mathrm{D}$ electrons in the conduction band leads to a situation when, in addition to electron transitions between the main bands, there are transitions between the valence band and the quantized level $e_{1}$ in the 2D quantum well. The presence of two transitions with energies $E_{g}$ and $E_{g}+e_{1}$ splits the peaks in the electroreflectance spectrum.

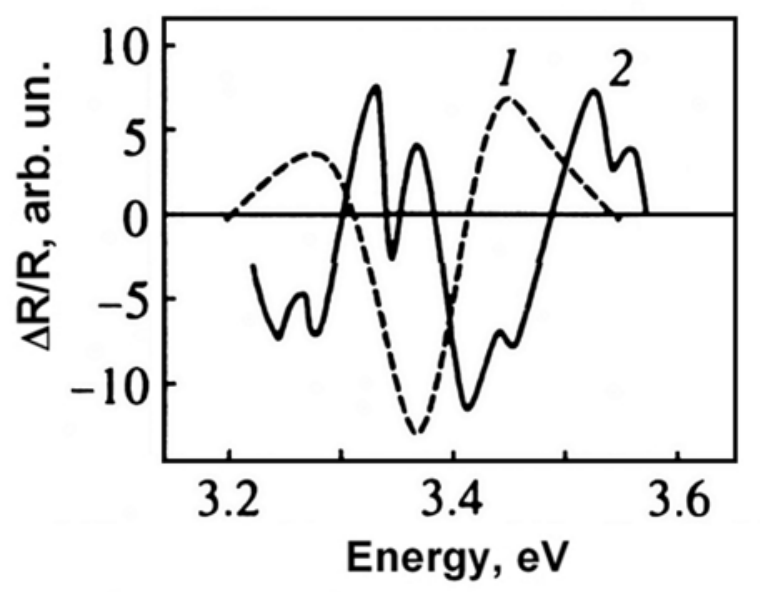

Fig. 1. Electroreflectance spectra of initial (1) and anisotropically etched (2) silicon surfaces in the $E_{0}$ transition region. 
The energy of optical transitions in the quantumsized system for the first quantization level is given by the expression

$e=E_{g}+\hbar^{2} \pi^{2} / 2 m^{*} L^{2}$

where $E_{g}$ is the band-to-band transition energy, $m^{*}-$ the band-to-band effective mass, and $L$ - width of the quantum well. The value $e_{1}=40 \mathrm{meV}$ found from the experimental electroreflectance spectra under the assumption that the effective hole mass is $m_{p}=0.49 m_{0}$ at the point $\Gamma_{25}^{\prime} \mathrm{C}$ and that the effective electron mass is $m_{e}=0.156 m_{0}$ (there $m_{0}$ is the free electron mass). With allowance for the expression (1), the width of the quantum well $L$ is $4 \mathrm{~nm}$.

Using the electroreflecance spectroscopy method, we also examined the microrelief $\mathrm{As}_{2} \mathrm{O}_{3}-p n n^{+}-\mathrm{GaAs}$ heterostructures [12]. On the Te-doped $n^{+}-\operatorname{GaAs}(100)$ substrate with electron concentration of $8 \cdot 10^{18} \ldots 2 \cdot 10^{19} \mathrm{~cm}^{-3}$ and thickness of $300 \mu \mathrm{m}$, we used the CVD method to deposite the 10...15- $\mu \mathrm{m}$ Si-doped

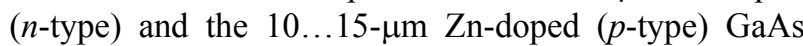
layers with the carriers concentration of about $8 \cdot 10^{16} \ldots 10^{17} \mathrm{~cm}^{-3}$. The microrelief heterostructures were formed on the frontal surface of the $p n n^{+}-\mathrm{GaAs}$ substrates by chemical etching in a $10 \ldots 15 \mathrm{~N} \mathrm{HNO}_{3}$ solution for $10 \mathrm{~s}$ at room temperature.

Fig. 2 depicts electroreflectance of $E_{1}$ and $E_{1}+\Delta_{1}$ transition for initial $p n n^{+}$-GaAs substrate (curve 1) and microrelief $\mathrm{As}_{2} \mathrm{O}_{3}-p n n^{+}$-GaAs heterostructure obtained using 10-s anisotropic etching (curve 2). Table 1 illustrates the electron zone parameters of $p n n^{+}-\mathrm{GaAs}$ substrate and relief $\mathrm{As}_{2} \mathrm{O}_{3}-p n n^{+}-\mathrm{GaAs}$ heterostructure: the $E_{1}$ and $E_{1}+\Delta_{1}$ energy transitions, the value of spinorbit splitting $\Delta_{1}$, the spectral broadening parameters $\Gamma_{1}$ and $\Gamma_{1+\Delta 1}$. The decease of $\Gamma$ parameters for the substrate in heterosystem caused by a good quality of the interface $\mathrm{As}_{2} \mathrm{O}_{3}-p n n^{+}$-GaAs. Such a feature is observed repeatedly, for example, at the $\mathrm{SiO}_{2}-\mathrm{Si}$ microrelief interface [11].

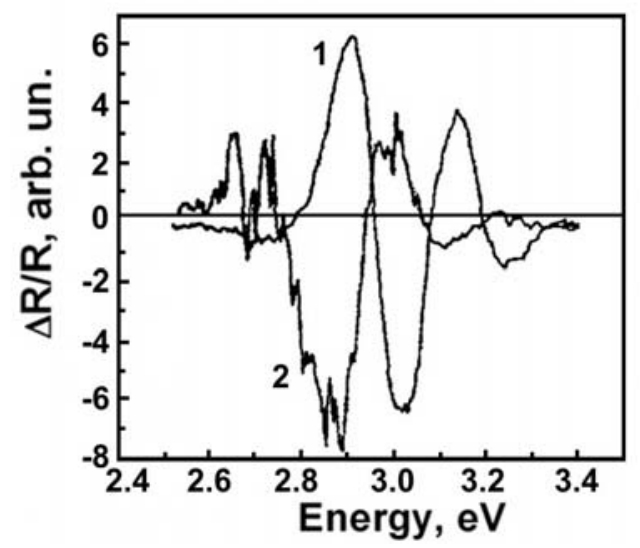

Fig. 2. Electroreflectance spectra of $p n n^{+}-\mathrm{GaAs}$ with flat (1) and microrelief $\mathrm{As}_{2} \mathrm{O}_{3}-\mathrm{GaAs}(2)$ surfaces.
Table 1. Effect of anisotropic chemical etching on zone parameters of $p n n^{+}-\mathrm{GaAs}\left(t_{\mathrm{ACE}}=10 \mathrm{~s}\right)$.

\begin{tabular}{|l|c|c|c|c|c|}
\hline \multirow{2}{*}{ Surface type } & \multicolumn{5}{|c|}{ Zone parameters, eV } \\
\cline { 2 - 6 } & $E_{1}$ & $E_{1}+\Delta_{1}$ & $\Delta_{1}$ & $\Gamma_{1}$ & $\Gamma_{1+\Delta 1}$ \\
\hline Non-patterned & 2.969 & 3.161 & 0.192 & 0.119 & 0.104 \\
\hline Patterned & 2.895 & 3.105 & 0.210 & 0.090 & 0.089 \\
\hline
\end{tabular}

In Fig. 2, there are two other remarkable features in the electroreflerctance spectrum of the microrelief sample: 1) inversion of signal polarity and 2) formation of a fine peaked structure, which is seen most clearly on the short-energy shoulder of the ER spectrum. These features may result from: 1) inversion of substrate conductivity type from $p$ to $n$ under formation of the inversion layer on $\mathrm{As}_{2} \mathrm{O}_{3}-p n n^{+}$-GaAs interface and 2) decrease in the heterosystem dimensionality from $3 \mathrm{D}$ to $2 \mathrm{D}$ for the carrier motion in the direction perpendicular to the interface. At the interface, the triangular quantum well (QW) appears with quantized levels (QL) in the two-dimensional electron gas channel. In Fig. 2, one can see 3 quantum levels.

Table 2 illustrates the energy of quantized levels $E_{n}$ and the width of quantum well $L_{n}$ at the $\mathrm{As}_{2} \mathrm{O}_{3}-$ pnn $^{+}$GaAs interface. In accordance with Table 2, the inversion layer is presented by the triangular quantum well with energy quantum levels of 36, 64 and $93 \mathrm{meV}$ on its width from 14 to $26 \mathrm{~nm}$.

It was applied GaAs surface passivation with sulphur to improve its structural perfection and electronic properties. Using the electroreflectance method, we investigated the real and chemically sulfided gallium arsenide surface within the spectral regions of $E_{0}$ and $E_{0}+E_{1}$ transitions. Natural oxide was removed from real surface of substrate by etching for $10 \mathrm{~min}$ in the mixture of $\mathrm{H}_{2} \mathrm{SO}_{4}: \mathrm{H}_{2} \mathrm{O}_{2}: \mathrm{H}_{2} \mathrm{O}=3: 1: 2$ and by washing in distilled water. Then, the samples were placed for 5 to $20 \mathrm{~min}$ in saturated solution of $\mathrm{Na}_{2} \mathrm{~S} \cdot 9 \mathrm{H}_{2} \mathrm{O}$ and illuminated with an incandescent lamp $500 \mathrm{~W}$. After washing with distilled water, the samples were dried in a stream of warm air. Under the action of photochemical reaction, the bonds $\mathrm{Ga}-\mathrm{As}$ were broken and the bonds $\mathrm{Ga}-\mathrm{S}$ appeared. Investigations of GaAs surface before and after its sulfidation were carried out in the spectral range of $1.3 \ldots 1.6 \mathrm{eV}$ for $E_{0}$ transition and $2.6 \ldots 3.4 \mathrm{eV}$ for $E_{1}$ transition. Fig. 3a shows electroreflectance spectra of initial surface (curve 1) and after its sulfidation (curve 2) for $E_{0}$ transition. Fig. $3 \mathrm{~b}$ shows the corresponding spectra for $E_{1}$ transition. In contrast to the initial surface of $\mathrm{GaAs}$, the electroreflectance signal from sulphided surface also appeared in the region $2.5 \ldots 2.65 \mathrm{eV}$. Its appearance can be explained by formation of $\mathrm{Ga}_{2} \mathrm{~S}_{3}$ sulphide coating with $E_{g}=2.55 \mathrm{eV}$ band [17]. The coating had a $p$-type conductivity, and $\Gamma=55 \mathrm{meV}$. 
Table 2. Energy position of quantum level $E_{n}$ on the width of quantum well $L_{n}$.

\begin{tabular}{|c|c|}
\hline The position of QL $E_{n}, \mathrm{eV}$ & Width of QW $L, \mathrm{~nm}$ \\
\hline 0.036 & 14.08 \\
\hline 0.064 & 21.11 \\
\hline 0.093 & 25.7 \\
\hline
\end{tabular}
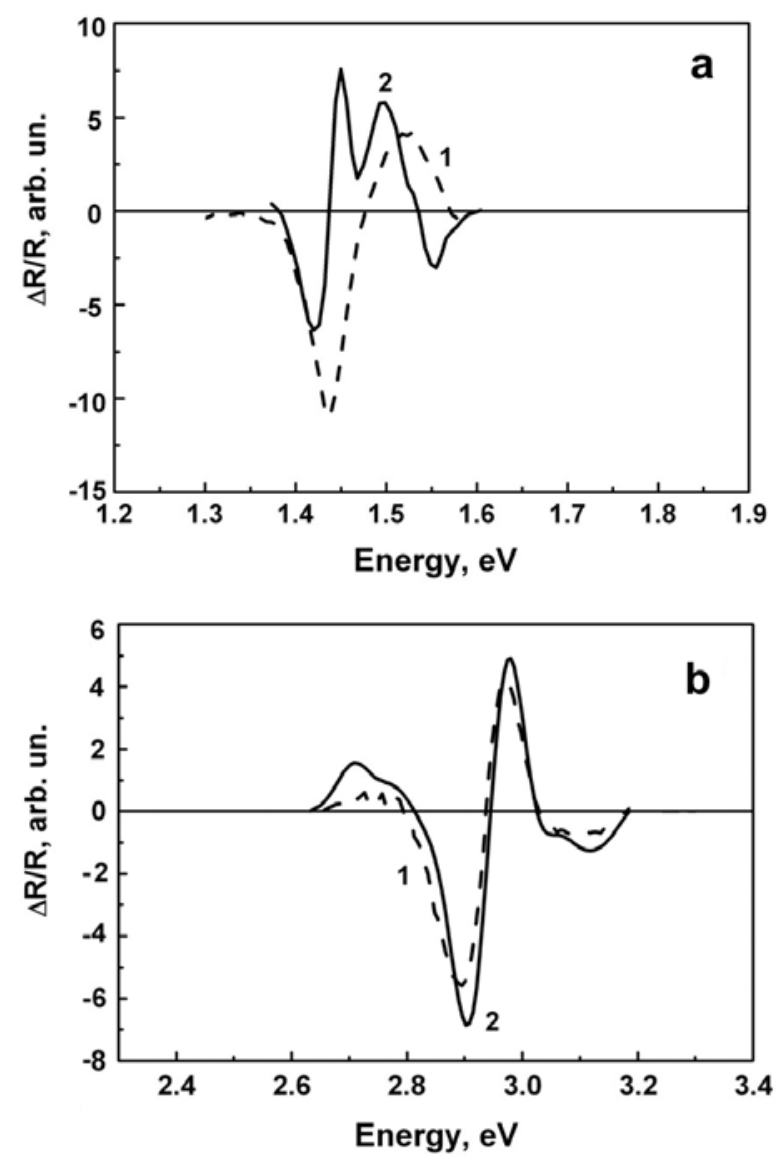

Fig. 3. Electroreflectance spectra of initial (1) and sulphurized (2) GaAs surfaces in the $E_{0}, E_{0}+\Delta_{0}$ (a) and $E_{1}, E_{1}+\Delta_{1}$ (b) transition regions.

Presented in Table 3 are electronic parameters of the electroreflectance spectra of GaAs surface for different duration of its sulphidation [18]. The decrease of $\Gamma$ value and increase of the energy relaxation time inherent to the excited light charge carriers $(\tau=\hbar / \Gamma)$ for both transitions is an evidence of electronic passivation of gallium arsenide surface after its sulphidation. Decreasing $E_{g}$ by $14 \mathrm{meV}$ for the transition $E_{0}$ and $7 \mathrm{meV}$ for $E_{1}$ is caused by occurrence of internal mechanical stresses $\left(1.3 \cdot 10^{8} \mathrm{~Pa}\right)$ in $\mathrm{Ga}_{2} \mathrm{~S}_{3}-\mathrm{GaAs}$ heterosystems [19]. Splitting the electroreflectance signal is associated with appearance of the surface quantum size effect in the heterosystem. In this case, the parameter $\Gamma$ is decreased and $\tau$ is increased at the interface, which lead to an increase in the free path of charge carriers and increases their mobility $\mu$.
Table 3. Electronic parameters of GaAs surface determined from electroreflectance spectra (region $E_{0}$ ) at different sulfidation time.

\begin{tabular}{|c|c|c|c|c|c|}
\hline $\begin{array}{c}t, \\
\mathrm{~min}\end{array}$ & $\begin{array}{c}E_{0}, \\
\mathrm{eV}\end{array}$ & $\Delta E_{0}, \mathrm{eV}$ & $\begin{array}{c}\Gamma, \\
\mathrm{meV}\end{array}$ & $\tau, 10^{-14} \mathrm{~s}$ & $\begin{array}{c}\mu, \\
\mathrm{cm} /(\mathrm{V} \cdot \mathrm{s})\end{array}$ \\
\hline 0 & 1.451 & & 80 & 0.82 & 2000 \\
\hline 5 & 1.437 & -0.014 & 32 & 2.05 & 3200 \\
\hline 10 & 1.397 & -0.054 & 36 & 1.82 & 3000 \\
\hline 20 & 1.390 & -0.061 & 51 & 1.29 & 2400 \\
\hline
\end{tabular}

The method of light electroreflectance spectroscopy was used to study crystals of $p$-type silicon, grown by the Czochralski method (specific resistivity was $10 \mathrm{Ohm} \cdot \mathrm{cm}$, oxygen concentration $-8 \cdot 10^{17} \mathrm{~cm}^{-3}$ ). Measurements of electroreflectance spectra were carried out in the spectral region of 3 to $3.8 \mathrm{eV}$ (direct transition $E_{0}$ in the centre of the Brillouin zone of $\mathrm{Si}$ ). The samples were irradiated with fast neutron fluence $10^{15} \ldots 10^{18} \mathrm{n} / \mathrm{cm}^{2}$ at $70^{\circ} \mathrm{C}$ [14]. Particular attention was given to preparation of its surface to measurements [20]. It was used isothermal annealing $\left(800^{\circ} \mathrm{C}, 700\right.$ hours $)$ in order to create the oxygen phase in crystals. The layer disrupted by mechanical polishing was removed by polishing etching in the mixture $\mathrm{HF}: \mathrm{HNO}_{3}: \mathrm{H}_{2} \mathrm{O}=1: 3: 1$.

The shape of electroreflectance signal depended on irradiation conditions and thermal treatment of the samples (the presence of oxygen-silicon precipitates, radiation defects). The electroreflectance spectrum of the initial sample was bipolar, $\Gamma=138 \mathrm{meV}$ (Fig. 4a, curve 1$)$. After annealing of the initial sample $\left(800^{\circ} \mathrm{C}\right.$, 700 hours), the broadening parameter of the spectrum decreased down to $68 \mathrm{meV}$. The spectrum has shifted to the high-energy region. The annealed sample (Fig. 4a, curve 2) $p$-type conductivity changed to $n$-type. Inversion of the signal due to formation of hightemperature thermal donors occurred in the process of annealing [21]. $E_{g}$ increase and decrease of the parameter $\Gamma$ is associated with a decrease of mechanical stresses and improvement of the structural quality of the sample surface after chemical treatment.

Neutron irradiation of the samples before annealing led to transformation of the structural defects in the crystal. Radiation defects on the surface of the sample formed at lower doses than in the bulk. Therefore, the surface layer of $15-\mu \mathrm{m}$ thickness was removed by chemical etching. At low doses, plate precipitates of crystalline phase (kristobalit) appear. With increasing of the neutron fluence, there occurred colony of microprecipitates (amorphous $\mathrm{SiO}_{2}$ ) [22]. Fig. 4b shows the electroreflectance spectra of silicon irradiated with the fluence $10^{18} \mathrm{n} / \mathrm{cm}^{2}$ before annealing (curve 1 ) and after annealing at $800^{\circ} \mathrm{C}$ (curve 2). On the curve 1 , two maxima are clearly seen at 3.325 and $3.403 \mathrm{eV}$. The splitting of the signal $(78 \mathrm{meV})$ in annealed silicon is caused by appearance of different areas of disorder in it (accumulation of divacancies or interstitial defects). 

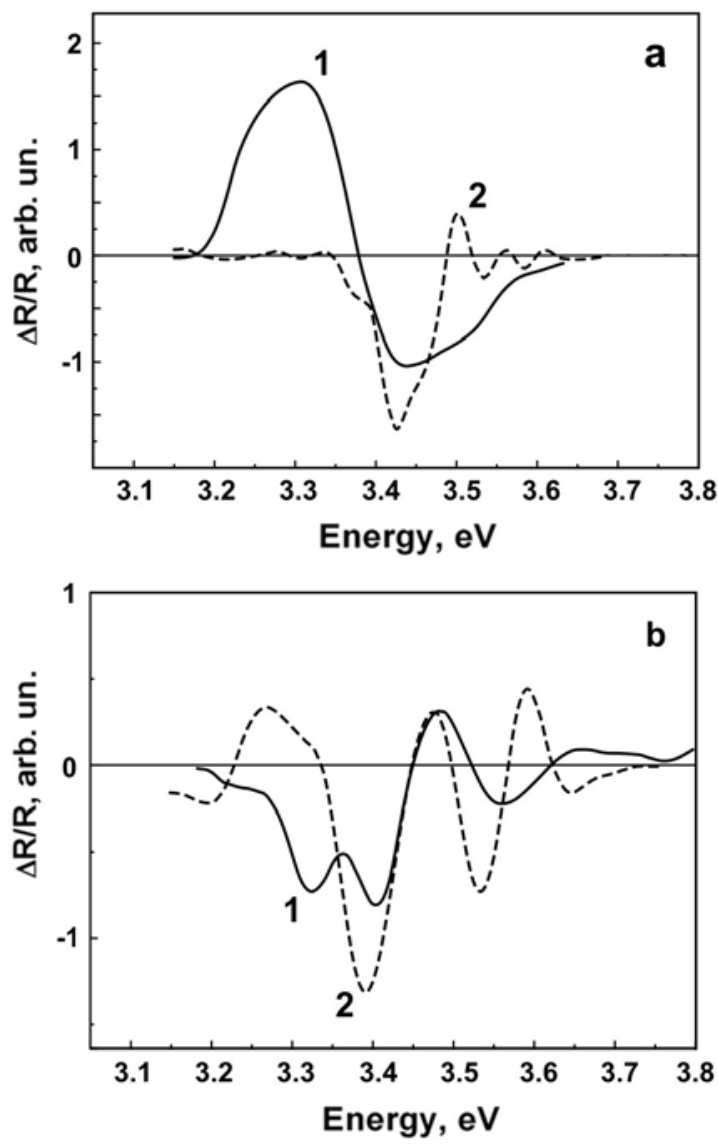

Fig. 4. Electroreflectance spectra of monocrystalline mechanically polished and chemically etched silicon: a) non-annealed before irradiation $(1)$ and annealed $(2) ; \mathrm{b})$ irradiation fluence $10^{18} \mathrm{n} / \mathrm{cm}^{2}$ non-annealed (l) and annealed (2).

Mechanical stresses change semiconductor band gap [23]. Vacancy type disordering in $\mathrm{Si}$ leads to appearance of tensile stresses and an increase of $E_{g}$ from 3.348 up to $3.403 \mathrm{eV}$. Interstitial defects create compressive stresses, and $E_{g}$ value decreases down to $3.325 \mathrm{eV}$. The local increase and decrease of $E_{g}$ in the sample splits of the electroreflectance signal.

After annealing at $800{ }^{\circ} \mathrm{C}$, the regions of both types of disorder and point radiation defects are annealed, mechanical stresses of different sign compensate one another, the defect structure of the sample improves, and there is a quantum-size effect (Fig. $4 b$, curve 2). During annealing of the irradiated samples, there appear thermodonors and electrically active particles of a new phase $\mathrm{SiO}_{\mathrm{x}}$. In the annealed sample, influence of the interface $\mathrm{SiO}_{\mathrm{x}} / \mathrm{Si}$ on the band structure of heterosystem and electronic processes in it increases with growth of the neutron fluence. The negative charge compensating positive charge in the oxide accumulates during the annealing process at the interface with silicon. Bands are curved down, and charge carriers are quantized in a triangular potential well at the interface. With increasing the irradiation dose, the energy of quantized level increases from 60 up to $85 \mathrm{meV}$, and the width of the quantum well decreases from 3 down to $2 \mathrm{~nm}$ [14].
The discovery of new carbon molecules $C_{n}$ called fullerenes has led to the appearance of a new class of carbon based solids and heterostructures [24, 25]. Among the famous fullerenes, $\mathrm{C}_{60}$ molecules are most symmetrical and stable. The carbon atoms in them have a covalent type of bonding, and the $\mathrm{C}_{60}$ molecules in the crystal have the weak bond corresponding to van der Waals interaction.

The $\mathrm{C}_{60}$ films were obtained using thermal evaporation of $\mathrm{C}_{60}$ powder in vacuum at pressure $10^{-4} \mathrm{~Pa}$ from an effusion tantalum cell at the temperature of $650 \mathrm{~K}$ on non-heated $n$-Si and cover glass substrates [15]. The thickness of films was $0.2 \mu \mathrm{m}$. Substrate material does not effect on the films structure at the deposition rate $5 \ldots 10 \mathrm{~nm} / \mathrm{s}$. According to [26], $\mathrm{C}_{60}$ fullerene films are a new direct band semiconductor with $E_{g}$ band gap value near $1.6 \mathrm{eV}$.

Fig. 5 presents the electroreflectance spectra of $\mathrm{C}_{60} / n$-Si heterosystem from the films surface (Fig. 5a) and from the interface (Fig. 5b). The band gap $E_{g}$ was $1.7 \mathrm{eV}$ for $\mathrm{C}_{60}$ film and $3.59 \mathrm{eV}$ for $\mathrm{Si}$ substrate. The $\mathrm{C}_{60}$ films on $n$-Si substrate have $p$-type conductivity and the weak splitting of the electroreflectance signal. The $\mathrm{C}_{60}$ film surface on $n$-Si substrate is depleted on electrons, and the bands are bent upward (Fig. 5a). Splitting of the electroreflectance signal indicates appearance of weak quantum-size effect in the film.
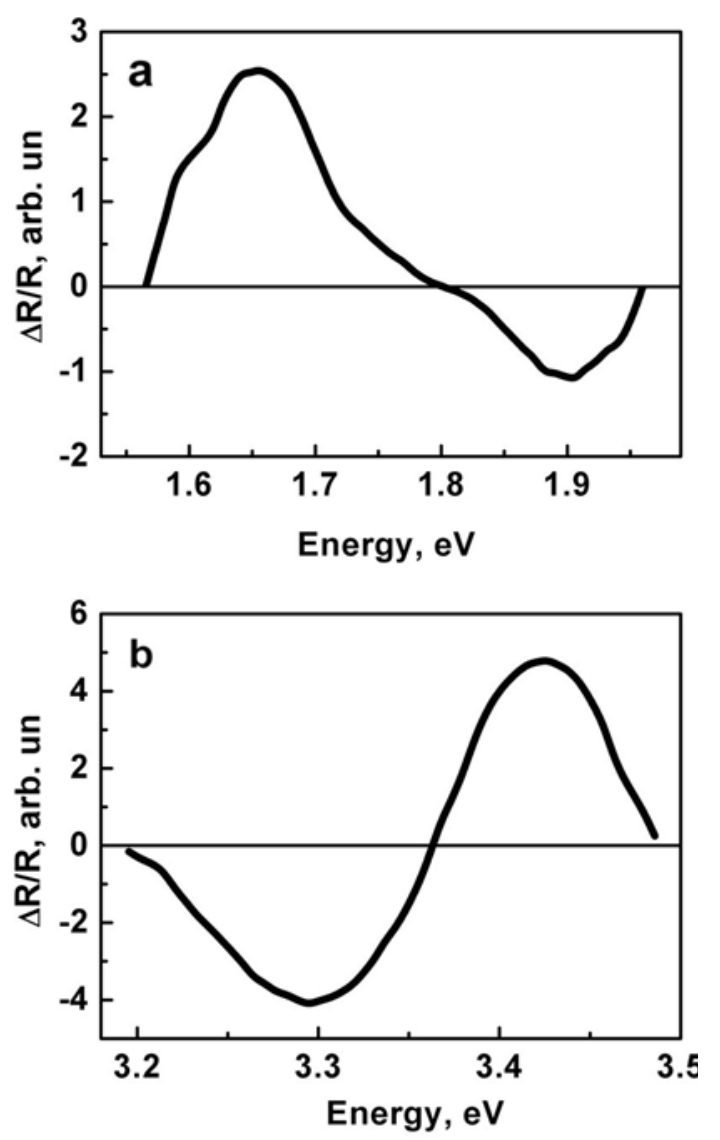

Fig. 5. Electroreflectance spectra of the film (a) and interface (b) in $\mathrm{C}_{60} / \mathrm{Si}$ heterosystem. 


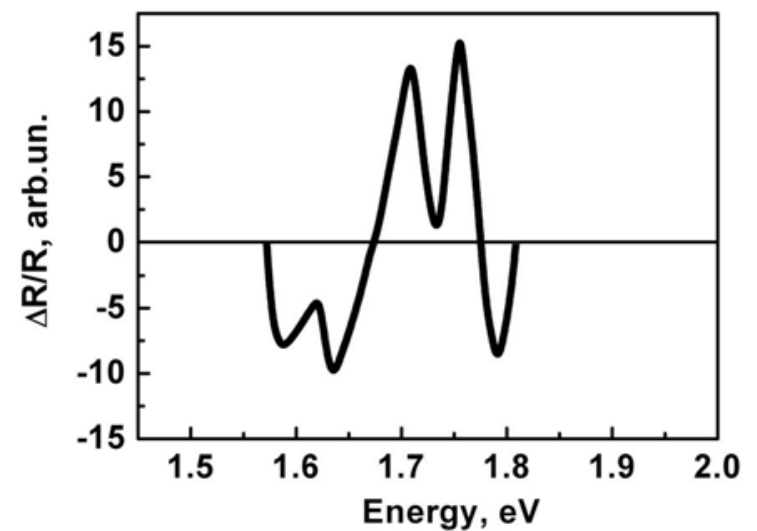

Fig. 6. Electroreflectance spectrum of $\mathrm{C}_{60}$ film on glass substrate.

The conductivity type of $\mathrm{C}_{60}$ film on the insulating glass substrate changed from $p$ to $n$, and the signal splitting increased (Fig. 6). At the interface, the film $\mathrm{C}_{60}$ is enriched with electrons, and the bands are bent downwards. The enrichment of the films with electrons contributes to appearance of interfacial electronic states. It causes a phase change of the electroreflectance signal in the $\mathrm{C}_{60}$ film on cover glass substrate [27]. The doublet nature of the electroreflectance peaks in $\mathrm{C}_{60}$ films on insulating substrate can be explained by the influence of surface quantization of electron energy in the enriched layer of $\mathrm{C}_{60}$ film on the interface (Fig. 6). The presence of two transitions with the energies $E_{g}=1.65 \mathrm{eV}$ and $E_{g}+e_{1}=1.7 \mathrm{eV}$ splintered peaks in the spectrum. The energy of quantum level $e_{1}=50 \mathrm{meV}$. For $E_{0}$ transition in $\mathrm{C}_{60}$ film, the hole effective mass $m_{p}$ is $1.3 m_{0}$, the electron effective mass $m_{e}$ is $1.5 m_{0}$. The reduced effective mass $m^{*}$ is $0.697 m_{0}$. For $50 \mathrm{meV}$ quantum level, the width of the quantum well is $2 \mathrm{~nm}$.

\section{Conclusion}

To obtain heterosystems with quantum size effect, the complex of technological methods was used. It included the anisotropic chemical etching of $p$-Si and $p n n^{+}-\mathrm{GaAs}$ surface, different doses of neutron irradiation and thermal annealing of $p$-Si crystals with the concentration of dissolved oxygen $8 \cdot 10^{-17} \mathrm{~cm}^{-3}$, the chemical sulfide passivation of $n$-GaAs (100) surface, $C_{60}$ fullerene thermal deposition on $n$-Si and cover glass substrates. Electrolytic method of modulation spectroscopy of light electroreflectance is a most sensitive to the band structure of semiconductors. Therefore, it was used for investigations of the band structure and electronic parameters of the surface and interface of the heterosystems with the quantum size effect.

The quantum size effect in heterosystems prepared using different methods appears as a result of inversion of semiconductor conductivity type (from $p$ to $n$ ) at the film-substrate interface. It leads to appearance of additional electronic transitions at the interface and splitting of the electroreflectance signal. Depending on the heterosystems manufacturing conditions and external influences, energies of the main electronic transition and quantized levels in a triangular potential well and the width of the well for each level, as well as broadening parameters of the spectra, the energy relaxation time of the excited light volume and quantized carriers were identified. Found in the patterned $\mathrm{As}_{2} \mathrm{O}_{3}-p n n^{+}-\mathrm{GaAs}$ heterosystems were 3 quantized levels with the energies 36,64 and $93 \mathrm{meV}$ for the widths of the quantum well $14.08,21.11$ and $25.7 \mathrm{~nm}$, respectively.

\section{References}

1. Andrievskiy R.A., Ragulya A.V. Properties of nanomaterials. Sized effects, Chap. 3 in: Nanostructural Materials. Moscow: Akademia, 2005. P. 60-66 (in Russian).

2. Ando T., Fowler A.B., and Stern F. Heterosystems, quantum wells and superlattices, Chap. 8, part 4 in: Electronic Properties of Two-dimensional Systems. Moscow: Mir, 1985. P. 324-332 (in Russian).

3. Paget D., Gusev A.O., and Berkovits V.L. Sulfidepassivated GaAs (001). II. Electronic properties. Phys. Rev. B. 1996. 53, No. 8. P. 4615-4622.

4. Kolyadina E.Yu., Matveeva L.A., Neluba P.L., Shlapatskaya V.V. Physical properties of $\mathrm{C}_{60}$ fullerene nanostructures. Mater. Sci. and Eng. Technol. 2013. 44, No. 2-3. P. 144-149.

5. Narajanan L.K., Jamaguchi M. Photovoltaic effects of a:C/C $\mathrm{C}_{60} / \mathrm{Si}(\mathrm{p}-\mathrm{i}-\mathrm{n})$ solar cell structures. Solar energy materials and solar cells. 2003. 75. P. 345350.

6. Dmitruk N.L., Borkovskaya O.Yu., Matveeva L.A., Mamikin S.V., Naumenko D.O. Photoelectric properties of microrelief metal-semiconductor heterojunction with an intermediate layer of $\mathrm{C}_{60}$ fullerene. Sbornik nauchnykh statey "Nanostructury $v$ kondensirovannykh sredakh", Minsk: Publishing Center of Byelorussian State University, 2008. P. 3-9 (in Russian).

7. Venger E.F., Gorbanyuk T.I., Matveeva L.A. Fullerenes and sensors. 5-th Int. Sci. and Techn. Conf. "Sensors electronics and microsystems technology" (SEMST-5). Ukraine, Odessa, June 48, 2012. P. 35-36 (in Ukrainian).

8. Cardona M. Modulation Spectroscopy. Moscow: Mir, 1972. 416 p. (in Russian).

9. Tyagay V.A., Snitko O.V. Semiconductors electromodulation spectroscopy, Chap. 7 in: Electroreflectance of Light in Semiconductors. Kiev: Naukova dumka, 1980. P. 174-237 (in Russian).

10. Yu. P., Cardona M. Quantum sized effect for electrons and phonons in semiconductors, Chap. 9 in: Fundamentals of Semiconductors. Moscow: Fizmatlit, 2002. P. 410-431 (in Russian).

11. Venger E.F., Gorbach T.Ya., Matveeva L.A., Svechnikov S.V. Spectroscopy of electroreflection, 
the electron band structure, and the mechanism of visible photoluminescence of anisotropical etched silicon. J. Experimental and Theoretical Physics. 1999. 89, No. 5. P. 948-954.

12. Gorbach T.Ya., Matveeva L.A., Smertenko P.S., Sukach G.A. Carrier transport properties, spectral photoresponse, and bandgap structure features in $p_{n n}{ }^{+}-\mathrm{GaAs}$ with patterned nanoscale $\mathrm{As}_{2} \mathrm{O}_{3}-\mathrm{GaAs}$ interface. Ukr. J. Phys. 2007. 52, No. 5. P. 480 488.

13. Matveeva L.O., Kolyadina O.Yu., Matiyuk I.M., Mischuk O.M. Structural perfection and electronic parameters of sulfided surface of Gallium Arsenide. Physics and Chemistry of Solid State. 2006. 7, No. 3. P. 461-467 (in Ukrainian).

14. Groza A.A., Litovchenko P.G., Matveeva L.O., Neluyba P.L., Pinkovska M.B., Starchyk M.I. The influence of neutron irradiation and thermal treatment on the appearance of self-organization, Franz-Keldysh and quantum size effects in monocrystalline silicon. Physics and Chemistry of Solid State. 2013. 14, No 1. P. 40-45 (in Ukrainian).

15. Neluba P.L. Peculiarities of fullerenes condensation from molecular beam in vacuum. Tekhnol. Konstr. Elektron. Appar. 2011. 6. P. 3539 (in Russian).

16. Aspnes D.E. Third derivative modulation spectroscopy with low-field electroreflectance. Surf. Sci. 1973. 37. P. 418-442.

17. Physical and Chemical Properties of Semiconductor Materials, Handbook. Eds. A.V. Novoselova and V.B. Lazareva. Moscow: Mir, 1978. 68 p. (in Russian).

18. Venger E.F., Matveeva L.O., Kolyadina O.Yu., Klimenko A.P. The influence of internal mechanical stresses and quantum size effect on the efficiency of sulphide electronic passivation of GaAs. Reports of the National Academy of Sciences of Ukraine. 2007. 7. P. 72-78 (in Ukrainian).
19. Goni A.R., Strössner K., Syassen K. and Cardona M. Pressure dependence of direct and indirect optical absorption in GaAs. Phys. Rev. B. 1987. 36, No. 3. P. 1581-1587.

20. Holiney R.Yu., Matveeva L.A., Venger E.F. Investigation of the undersurface damaged layers in silicon wafers. Semiconductor Physics, Quantum Electronics \& Optoelectronics. 1999. 2, No. 4. P. 10-12.

21. Babich V.M., Bletskan N.I., Venger E.F. Oxygen in the Silicon Single Crystals. Kiev: Interpress Ltd, 1997. 239 p. (in Russian).

22. Groza A.A., Venger E.F., Varnina V.I. et al. Influence of neutron irradiation on electrooptical and structural properties of silicon. Semiconductor Physics, Quantum Electronics \& Optoelectronics. 2001. 4, No. 3. P. 152-155.

23. Dargus D. and Kundrotas J. Handbook on Physical Properties of Ge, Si, GaAs and InP. Vilnius: Science and Enciclopedia Publishers, 1994. 264 p.

24. Eletskii A.V., Smirnov B.M. Fullerenes and carbon structures. Phys.-Usp. 1995. 38, No. 9. P. 935-964.

25. Makarova T.I. Electrical and optical properties of pristine and polymerized fullerenes. Semiconductors. 2001. 35, No. 3. P. 243-278.

26. Kolyadina E.Yu., Matveeva L.A., Neluba P.L., E.F. Venger Analysis of the fundamental absorption edge of the films obtained from the $\mathrm{C}_{60}$ molecular beam in vacuum and effect of internal mechanical stresses on it. Semiconductor Physics, Quantum Electronics \& Optoelectronics. 2015. 18, No. 3. P. 349-353.

27. Kolyadina E.Yu., Matveeva L.A., Neluba P.L., Venger E.F. Nanotechnology, Features of Surfaces and Interfaces in the Nanostructures with $\mathrm{C}_{60}$ Fullerenes and Carbon Composite Films. Proc. Int. Conf. "Nanomaterials: Applications and Properties" (NAP-2016), September 14-19, 2016, Sumy, Ukraine. 5. P. 01PCI03-1-4. 